\title{
Chapter 17 \\ Linear Increase in Life Expectancy: Past and Present
}

\author{
Tommy Bengtsson
}

Improvements in human stature, real income and life expectancy have taken place at an unprecedented speed during the last 200 years. In the case of life expectancy at birth, the record has been broken at an amazingly constant pace since 1840 . Females have continuously gained 2.92 months per year, males slightly less (Oeppen and Vaupel 2002). While the increase is considerable, with improvements in life expectancy of some 8 years from parent to child, it is the regularity of the advancement that is remarkable, not the speed as such. The reason is that the countries entering the mortality transition at a later stage in history tend to exhibit an even faster improvement. Japan, for example, experienced improvements of 6 months per year in life expectancy during its catch-up in the twentieth century. In China the corresponding figure was well above 1 year in the 1960s and 70s. Thus, while the increase of bestpractice countries is not astonishing in itself, the linearity of the improvement certainly is. This raises obvious questions: What are the causes of this linear increase and how long can it be sustained? Other questions concern whether the observed linear increase in life expectancy can be used in forecasting life expectancy both for countries lagging behind and countries in the lead.

To Oeppen and Vaupel, the linear development of life expectancy suggests that the process of mortality reductions "should not be seen as a disconnected sequence of unrepeatable revolutions but rather as a regular stream of continuing progress" (Oeppen and Vaupel 2002:1029), referring to Lee and Carter (1992), and Tuljapurkar et al. (2000). Still, in the next sentence Oeppen and Vaupel state, with reference to Riley (2001), that mortality improvements are the result of a complex process of "advances in income, salubrity, nutrition, education, sanitation, and medicine, with the mix varying over age, period, cohort, place, and diversity" (Oeppen and Vaupel 2002:1029). Thus, on the one hand the advance in life

\footnotetext{
T. Bengtsson ( $\square)$

Centre for Economic Demography, Lund University, Lund, Sweden

e-mail: tommy.bengtsson@ekh.lu.se 
expectancy is a regular stream of continuous progress but on the other it is also an intricate interplay of a mixture of social, economic and medical factors, which sounds almost like a paradox that calls for further clarification. As starting point, I will take a closer look at the countries that are the leaders in life expectancy: a very small number indeed, consisting of nine countries altogether. What mixture of factors varying over age, period, cohort, diversity of diseases, and place has made them the global leaders of life length? I will then turn to the issue of causality.

\subsection{Descriptive Overview}

Starting with age and period, to quote Oeppen and Vaupel (2002:1029), "most of the gain in life expectancy was due to large reductions in death rates at younger ages. In the second half of the 20th century, improvements in survival after age 65 propelled the rise in the length of people's lives". This is indeed one of the most well-known and universal facts regarding the historical mortality transition. It holds true both for countries that have experienced the mortality decline recently and for those where it started hundreds of years ago. In Sweden, an example of the latter, the level of infant mortality dropped almost without interruptions from the mid-eighteenth century onwards. The other Nordic countries showed a similar development (Bengtsson and Lundh 1999). England and other parts of Western Europe, as well as North America, initially followed the same pattern of infant mortality decline in the eighteenth and the beginning of the nineteenth century but after that point in time, the decline levelled out. Alfred Perrenoud (1984) consequently differentiates between a Nordic model, with continued decline, and a West-European model, with an interrupted decline. From around the end of the nineteenth century to present day, however, all countries in the industrialized world have exhibited the same development of rapid decline in infant and child mortality, which was the main reason for the rise in life expectancy. Though death rates for the elderly started to drop already in the latter part of the nineteenth century, it was not until the mid-twentieth century that life expectancy was largely propelled by falling mortality at age 65 and above. Since the change from infant and child mortality to mortality among the elderly as the major explanation of the observed improvements in life expectancy has not yet occurred in many countries, most of the increase in life expectancy during the twentieth century in these countries has still been due to the decline in infant and child mortality.

Another striking and commonly-shared pattern is the change over time in the diversity of diseases. Here Oeppen and Vaupel refer to Bongaarts and Bulatao's volume Beyond Six Billion (2000) and Riley's book Rising Life Expectancy: A Global History (2001). In turn, Riley's way of reasoning is much in line with the Epidemiological Transition Theory, according to which the pestilences and famines are followed by receding pandemics, and later by degenerative and man-made diseases (Omran 1971). This line of theory argues that the changes are mainly the result of man's control over his environment. How mortality patterns change over 
time is not the object of much controversy; more so the causes behind these changes. General agreement prevails that decline in infant and child mortality starts off in the form of reduced mortality in highly virulent infectious diseases but is upheld by a decline in less virulent infectious diseases. The role of famines in this process is more debated but it is unlikely that it has influenced trends in infant and child mortality to any significant degree (Wrigley and Schofield 1981). Thus, it was a reduction in the mortality among children in highly virulent diseases, primarily a drop in smallpox mortality, together with further reductions in mortality in low virulent infectious diseases, which brought the best-practice countries to the lead in 1840 .

The second crucial change came after the mid-twentieth century and consisted of the fall in mortality in ages 65 years and above. This decline was largely caused by reductions in chronic diseases (cardiovascular, cerebrovascular and some cancer diseases), possibly in combination with a general health amelioration due to improvements of conditions in early life in the beginning of the twentieth century. In fact, when the great mortality decline of Western Europe was first analysed by Derrick (1927) and Kermack et al. (1934), they clearly advocated the role of cohort factors. They believed that the decline in adult mortality in England, Wales, and Scotland, as well as in Sweden, to a large extent was the result of improved conditions in childhood. This argument later lost ground as the Demographic Transition Theory evolved and the process of modernization and other period factors came into focus (UN 1953). It was not until the late seventies that Preston and van de Walle (1978), Fridlizius (1989) and later Barker (1994) and Fogel (1994), brought these issues into play again. Today, there is an extensive and lively debate on the importance of early-life factors on mortality in later life vis-à-vis period factors.

Regarding place, it is striking that so few countries have been record-holders in female life expectancy over the past 160 years, as shown in Table 17.1. The linear line is based on the experience of only nine countries, starting off with Sweden and Norway in the first two decades after 1840, and followed by Australia in the 1860s. New Zealand came into the lead in 1876 and almost monopolised this position until

Table 17.1 The nine world record holding countries

\begin{tabular}{lrll}
\hline Country & Years in lead & Starting year & Last year \\
\hline Sweden & 10 & 1840 & 1973 \\
Norway & 48 & 1841 & 1969 \\
Australia & 8 & 1861 & 1920 \\
New Zealand & 57 & 1876 & 1947 \\
Denmark & 2 & 1918 & 1919 \\
Iceland & 19 & 1941 & 1984 \\
The Netherlands & 1 & 1964 & 1964 \\
Switzerland & 1 & 1985 & 1985 \\
Japan & 15 & 1986 & 2000
\end{tabular}

Source: Oeppen and Vaupel (2002, Supplementary Material, Table 2) 
1941, with the exception of a brief period between 1916 and 1919 when first Sweden and then Denmark surpassed all others. During the Second World War, Norway and Sweden, now in company with Iceland, showed the best-practice levels in life expectancy and remained leaders until 1986 when Japan took over the lead position. Except for 2 years, during which the Netherlands and Switzerland respectively out-performed all other countries, Japan has continued to hold the world record until the present day. Thus, three of the nine countries demonstrate outstanding life expectancy figures for very limited periods, i.e. a year or two, and for one of these, Australia, annual data is in fact lacking. Only two single values are used for Australia, of which one is used to cover a 7-year period in the 1860s and 1870s (Oeppen and Vaupel 2002, Supplementary Material, Table 2). ${ }^{1}$ That leaves five countries which among them share the world record for 148 out of the 160 years that the analysis covers: Sweden, Norway, New Zealand, Iceland, and Japan. The focus will hence be placed on these five leading nations.

Sweden and Norway have the highest levels of life expectancy from 1840 until data become available for New Zealand in 1876. For a decade, the New Zealand level exceeds the two Nordic countries with almost 5 years. However, the improvement is somewhat faster in the two Nordic countries than in New Zealand, which means that they converge and finally catch-up in the beginning of the 1940s, as shown in Fig. 17.1. This is the period in which the decline in infant and child mortality drives up life expectancy. It is also the period when mortality in low virulent infectious diseases declines. Thus, the question is what makes these three countries stay ahead of all others as regards mortality in infectious diseases among infants and children during this 100-year period. Further, if comparing the three, why is New Zealand unable to improve as fast as Sweden and Norway and keep its superiority?

In the period after the Second World War, in the countries that started the mortality decline in the nineteenth century, life expectancy was mainly driven by reductions in mortality among the elderly due to a reduction in chronic diseases. Up until 1985, when Japan took over the lead, Iceland, and for some years Norway and Sweden, exhibit the highest life expectancy rates. It is noticeable that while New Zealand, Norway, Sweden, and also Iceland, level off as they come into the phase where life expectancy no longer mainly is driven by reductions in infant and child mortality, Japan does not. Once again, the question is what factors make these five countries more successful than the rest of the world.

\footnotetext{
${ }^{1}$ The data that Oeppen and Vaupel use stems from Rowland and cover periods between 9 and 16 years in length. The value for 1861-63, 1867-68, and 1874-75, when Australia is in lead, is based on the average of the period 1860-1875, in which the value is lower than for Norway. Since we don't know if it in the lead in any of these particular years or not, we leave Australia out of the following discussion.
} 


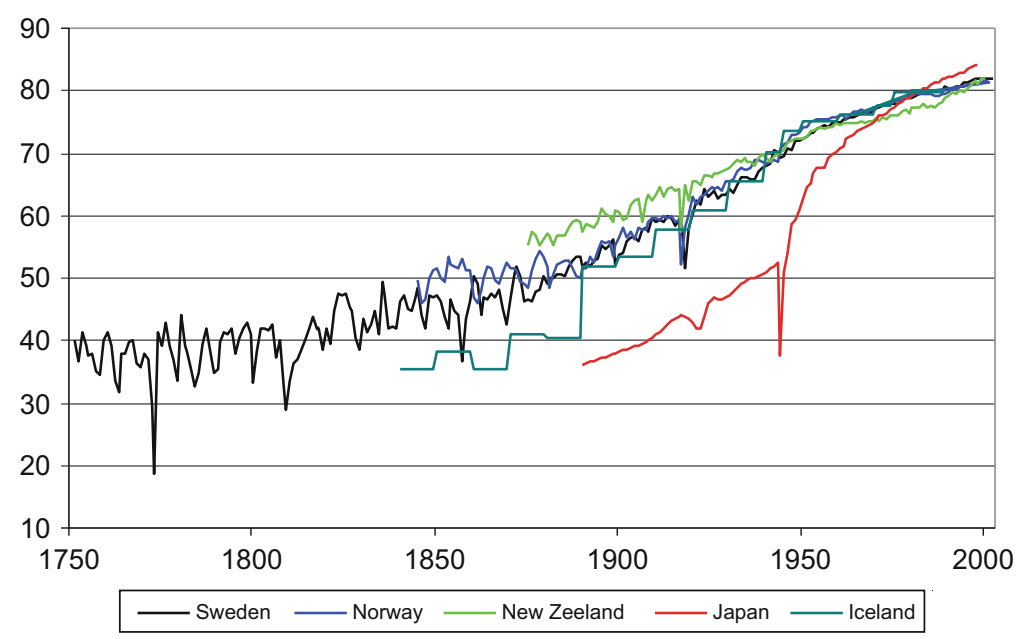

Fig. 17.1 Female life expectancy 1751-2001. (Sources: The Human Mortality Database, University of California, Berkeley (USA), and Max Planck Institute for Demographic Research (Germany), available at www.mortality.org or www.humanmortality.de (data downloaded on 7 October 2005); Hagskinna. Icelandic Historical Statistics (1997). Jónsson G. and M.S. Magnússon (eds.); and Nanjo and Kobayashi (1985))

\subsection{Causes}

Beyond Six Billion by Bongaarts and Bulatao (2000:117-123), which Oeppen and Vaupel refer to as regards changes in lethal diseases, not only gives an overview of the diversity of diseases during various phases but also supplies an explanation much in line with Riley (2001) and Omran (1971) and which can be summarised as follows:

1st stage 1700-1800.

Reduction in volatility/epidemics due to

1. more stable consumption (better storage and transportation) giving higher resistance

2. decline in virulence of pathogens

2nd stage 1800-1900.

Reduction in infectious diseases (influenza, pneumonia, bronchitis, TB, and smallpox) due to

1. increasing standard of living through improved health behaviour

2. public health measures including smallpox vaccination

3rd stage 1900-1960.

Reduction in infectious diseases due to

1. reduced exposure

2. reduced transmission 
4th stage 1960-1996.

Reduction in chronic diseases (cardiovascular, cerebrovascular and some cancer diseases) due to

1. early detection and prevention

2. improvement in surgical procedures

3. refinement of medical therapies

The question is whether these factors explain why the five countries are in the lead and why the development of female life expectancy is linear. How well did Norway, Sweden and New Zealand do in terms of standard of living, improved health behaviour, and public health measures in comparison to other countries up until the Second World War?

Regarding Norway and Sweden, they did not perform well in terms of living standards in the latter 1800s. GDP per capita in 1870 (in 1990 international dollars) was low compared with the US, the Netherlands and England, as shown in Table 17.2.

While real wages for workers in Sweden increased after 1870 (Bengtsson and Dribe 2005; Jörberg 1971), we are less certain of the development prior to that. In fact, during the first part of the nineteenth century, the majority of people might even have been worse off than during the eighteenth century (Bengtsson and Dribe 2005). GDP per capita for Norway was even lower than for Sweden. In New Zealand, GDP per capita was well above the Nordic countries, to the extent that it was almost on a par with the most advanced European countries. While the ranking of New Zealand versus the two Nordic countries correctly reflects their position regarding life expectancy, the rest is contrary to what we could expect given the countries' economic performance.

The Nordic countries are today known for their flat income distribution. Historically, though, this has not been the case. The income distribution in the beginning of the nineteenth century - a period of commercialization of agriculture and rapid economic transformation - was most likely spread. Several indicators show that while the income for landowners increased, it decreased for non-landed groups making the latter more vulnerable to variations in food prices (Bengtsson 2004; Bengtsson and Dribe 2005).

Turning to health behaviour, we have no evidence that Norwegians and Swedes were better-off than other Europeans; rather the opposite. Malthus, for example,

Table 17.2 GDP per capita in 1870 (in 1990 international dollars)

\begin{tabular}{ll}
\hline Country & GDP/capita \\
\hline United Kingdom & 3191 \\
Netherlands & 2753 \\
United States & 2445 \\
New Zealand/Australia/Canada & 2339 \\
Sweden & 1664 \\
Norway & 1432 \\
\hline
\end{tabular}

Source: Maddison (2001, Table B-21) 
reports from travelling in Scandinavia that Swedes were dirty and poorly fed (James 1966:67). They did not even have proper inns for travellers. Malthus statement refers to the beginning of the nineteenth century but similar depictions can be found well into the 1930s, when the depreciatory concept Lortsverige (Dirty-Sweden) was coined (Nordström 1938).

Riley claims that Sweden was very successful in terms of public health measures (Riley 2001). He states that the vaccination campaigns eradicated smallpox. While it is true that Sweden experienced rather few deaths in smallpox mortality after vaccination started in 1801, most of the decline in smallpox mortality, nevertheless, took place before this time (Bengtsson 1998, 2001; Sköld 1996). Smallpox vaccination was not the only public health improvement undertaken. Other measures include breast-feeding campaigns, education of midwives, disease control, investments in water supply and sewage systems, and promotion of improved personal hygiene.

Without doubt, investments in water supply and sewage control did have effects on mortality in urban areas after c. 1880, even more so in more urbanized countries than Norway and Sweden, both of which both were predominantly rural countries at this time. In fact, most cities in both Norway and Sweden in the mid-nineteenth century, when the two were in the lead, were small; no more than large villages by contemporary West European standards. By the same standards, only the two capitals could rightly be defined as cities, which gave Norway and Sweden a comparative advantage at a time when water supply and sewage control still were insufficient in most urban regions. The urban toll was thus less heavy in less urbanized countries, like Sweden and Norway, than in the more developed parts of Western Europe.

As for other public health measures, such as the breast-feeding campaigns that took place in Sweden from the 1830s and onwards, a certain local impact in areas where breast-feeding was uncommon was reported (Brändström 1984), but the influence on national levels of infant mortality was slight. Incidentally, childhood mortality in fact went up in Sweden during the period when these campaigns started (Fridlizius 1984). Other measures, like the training of midwives, commenced about the same time as the breast-feeding campaigns. Taken together, it is likely that they had some impact on the infant mortality decline from around the 1830s onwards.

The question of improved storage of food and other undertakings aimed at stabilizing consumption which, according to Bongaarts and Bulatao (2000) were important for the mortality reduction in the eighteenth century, constitutes a controversial issue. Firstly, we have no evidence of such measures being taken in the Nordic countries and secondly, it is unlikely that such initiatives would have influenced trends in infant and child mortality to any significant degree (Wrigley and Schofield 1981).

To summarize, Sweden and Norway had no advantage in terms of living standards or equal income distribution in the nineteenth century when they exhibited the highest level of recorded life expectancy in the world. Neither were they particularly well-organized with regard to, for example, the poor relief system. However, several public measures, like the above mentioned education of midwives and breast- 
feeding campaigns, were carried out in order to improve public health. They were also favoured by a low degree of urbanization. But perhaps most important of all, they were lucky to escape from highly virulent diseases, i.e. smallpox, even before vaccination programs started.

For New Zealand, which held the position of world leader in life expectancy for 57 years of the 160-year period, other factors were instrumental. In 1876, the first year data is available for New Zealand, there are indications showing that the country's white population was the most long-lived on Earth and that the level of living standard was well above the Nordic countries, as well as most other countries of the world. The situation also differed in that a large share of its rapidly increasing population was made-up by immigrants. Furthermore, not only is it reasonable to assume these immigrants to be of reasonably good health, in particular considering that they had travelled long distance, most of them were selected for their qualities and also underwent at least one health test, for phthisis (Pool and Cheung 2005). New Zealand also became a well-organized society with an expanding public sector. It can easily be compared to Britain in terms of health organisation and institutions but without the burden of large cities and with a selected population, thus almost as a natural experiment with the UK as a point of departure. ${ }^{2}$ Still, however, improvements in life expectancy were slower than in Norway and Sweden. Thus, the lead for New Zealand is much a result of its initial superiority: a selected, well-fed, wellorganized population in combination with a low disease load.

In comparing New Zealand with Norway and Sweden, and the three of them with the rest of the world, it is difficult to distinguish any "regular stream of continuing progress" that could explain why these three specific countries on a global scale perform so outstandingly in life expectancy. It is seemingly a basket of factors, partly different in New Zealand from the two Nordic countries, which make them stay at the top. They share the low degree of urbanization and a low disease load and differ in terms of economic resources. They are well-organized in that public schooling was introduced early and that they took public measures to improve health, but so did many other countries without advancing to the lead position and without contributing to the linear development of life expectancy.

Moving on to the latter part of the twentieth century, this period is characterised by propelled life expectancy due to declining death rates among the elderly, mainly as an effect of mortality reduction in chronic diseases (cardiovascular, cerebrovascular and some cancer diseases). According to Bongaarts and Bulatao (2000) this is brought about by early detection and prevention of diseases, improvements in surgical procedures, and refinements of medical therapies. The question is why Iceland and, post-1986, Japan perform better than all other countries within these areas.

Starting with Iceland - the world leader for 19 years between 1941 and 1984 - it has an historical development that sets it apart from the other Nordic countries.

\footnotetext{
${ }^{2}$ Jim Oeppen made this point during the workshop that this volume is based on. He also noticed that life expectancy on the English country side was on a par with New Zealand during the latter part of the nineteenth century.
} 
While Iceland had a stagnant population throughout the nineteenth century, the other countries experienced steady population growth. In addition, mortality was higher and life expectancy was lower than in any of the other Nordic countries. The Icelandic life expectancy at birth during the 1880s is about 10 years less than Norway and Sweden. In the last decades of the nineteenth century and in the beginning of the twentieth century, however, mortality drops dramatically and in the 1940s, Iceland is on a par with Norway and Sweden, as shown in Fig. 17.1. Causing the catch-up is a fall in infant and child mortality. Due to the high infant and child mortality in the latter part of the nineteenth century, the proportion surviving to ages above 65 years in the 1940s was very low compared with the countries in the lead. Thus, the population at risk in Iceland is constituted in a different way than New Zealand, Norway and Sweden since the females in older ages represented a much smaller proportion of their birth cohorts than in the other three countries. As the difference with the other countries diminishes, Iceland follows the same pattern of life expectancy as Norway and Sweden. In some of the years in the post-World War II period their life expectancy is slightly higher, in some years it is lower.

Japan differs somewhat from the other countries and had it not been for this country, the linear development would have been interrupted by the 1980s since the life expectancy in Iceland, Norway, Sweden, and New Zealand is levelling off. Japan is a country with a very high income level, attained only over the last decades. Previous to its rapid economic development from the 1960s onwards, the situation was less favourable and life expectancy was rather low. In fact, Japan is an example of one of the newly industrialized countries that have shown a tremendous development during the course of the twentieth century. Life expectancy for women rose from 60 years in 1950 to 80 years in 1984. This is not a development of life expectancy by 2.92 but by 6.00 months per year! Is this due to early detection and prevention of diseases, improvements in surgical procedures, and refinements of medical therapies causing mortality among the elderly to decline? It is surely not; rather it is an exemplary case of the catch-up of a rapidly developing country. The increase in life expectancy is not mainly driven by mortality improvements solely among the elderly but within a wider age span.

The rapid change in Japan also has some characteristics in common with Iceland that are important in making comparisons with the old leaders. The rapid transition from high to low mortality within a short period of time means fewer elderly relatively speaking. For example, while $90 \%$ of the women born in Sweden in 1935 have reached the age of 65 years, the corresponding figure for Japan is only $60 \%$. Thus the population age structure in 2000 is entirely different in Japan comparative to Sweden. This has two implications. First, the Japanese women at higher ages contributing to the period life-expectancy in year 2000 are highly selected in comparison to the Swedish older women. If the "scarring" effect is

\footnotetext{
${ }^{3}$ Based on data from Population Statistics of Japan 2003, complied by National Institute of Population and Social Security Research, Japan, and Befolkningsutvecklingen under 250 år (Population Development in Sweden in a 250-year perspective), Demografiska rapporter 1999:2, Statistics Sweden.
} 
smaller than positive selection effects then the Japanese elderly would be expected to be less fragile than their Swedish counterparts ${ }^{4}$. Second, due it its late fertility transition, the elderly are relatively speaking fewer in Japan compared with Sweden. While the proportion 65 years and over in Sweden reached 8\% in 1900, the corresponding figure was reached in Japan more than 70 years later. Because the Japanese elderly are fewer, relatively speaking, the costs for pensions and care are smaller for the Japanese vis-à-vis the Swedish working generation.

\subsection{Summary and Discussion}

We started off by pointing out that very few countries, only nine, have held the leading position in life expectancy at birth over the last 160 years, and only five of them did so for more than a few years. Typically, new countries caught up with and replaced former best-practice countries for several decades. However, we can note that this has not only been the case for life expectancy but has also occurred in other areas of human activity, such as economic performance. The total number of leaders in GDP per capita corresponds in size to the number of leaders in life expectancy, albeit they are not the same countries. The list of GDP leaders, ranked from high to low according to years at the lead and for roughly the same period, is as follows: the USA, Australia, Switzerland, the UK, and New Zealand (Maddison 2001). The fact that this list is different from that for life expectancy, emphasizes the relevance of Easterlin's conclusions that the mortality decline since the mid-nineteenth century was not mainly driven by economic development (Easterlin 1999). Instead, there are a variety of factors that lie behind the improvements in life expectancy, economic factors constituting only one of these.

High life expectancy in Sweden and Norway in the mid-nineteenth century was due to low infant and child mortality, in particular in infectious diseases. It was not the result of private or societal investments, strong nation-states, high living standards or an equal income distribution. What favoured the Nordic countries was instead a low degree of industrial development and urbanization combined with a low disease load. When New Zealand took over the lead position in 1876 (the first year for there is data), it shared these favourable characteristics of the two Nordic countries, in addition to other favourable conditions such as high income levels and a positively selected population.

Mortality in all age-groups dropped quickly in the early twentieth century but the improvements in life expectancy were still mainly due to the decline in infant and child mortality. During this period it was largely due to societal investments of reducing disease exposure; directly through eradication programs, indirectly through water purification systems and better transportation. This was the case for the most developed countries. For example, the previously large differences between hospital wards in many US cities disappear within a few decades (Fogel 2004). The same

\footnotetext{
${ }^{4}$ See Preston et al. 1998, p. 1232.
} 
process was at hand in countries like Singapore, Sri Lanka, Argentina, Costa Rica, Chile, Cuba, and Uruguay, which later affected the mortality transition (Bongaarts and Bulatao 2000:124). Still, none of these countries reached the highest level of life expectancy. New Zealand remained in the lead and it was instead the Nordic countries, making the same sorts of societal investments, which caught up in the 1940s. Thus, societal investments in infrastructure and high per capita income alone were not that important in determining life expectancy at birth. If this were the case, the US, the UK, Australia, and New Zealand would be at the top.

Iceland had been lagging far behind the leading nations when it started its catch-up which brought it to lead in the 1940s, and for Japan this was even more the case before it became the world leader in the 1980s. Both countries, especially Japan, had a very small elderly population when reaching the top position in terms of life expectancy. Today, life expectancy in the developed countries is not entirely the result of low infant and child mortality, as used to be the case, but instead old age mortality has become important. Medical care and private investments in health are also of greater significance nowadays. Thus Japan had the advantage of rapid improvements in living standards and societal investments in infrastructure, facilitated by access to new types of medical care, all of which they share with the most advanced countries of the world. In addition, they have a smaller group of elderly in the population. This means that the elderly are a selected group. Since the proportion of elderly is lower in Japan due to its late fertility decline, it also means, ceteris paribus, that Japanese senior citizens will have access to more care resources than their equals in countries that have experienced an earlier fertility transition.

Why then has life expectancy in the flow of best-practice countries followed a linear trend for a 160 year period? It is hard to find any specific continuous process that explains such a development. It resembles more the outcome of a diversity of processes, of which some but not all are directly related to human activity. If one compares with economic performance, it is reasonable to ask why life expectancy does not follow the exponential trends of economic output, the signum of economic growth ever since Malthus wrote his first essay, but instead only a linear trend? As regards economic development, more resources create more resources for good investments, thus generating an exponential trend. In the Malthusian world, population expanded at an exponential rate and production at a linear rate at best. Here we are confronted with the opposite situation: The economy expands at an exponential rate while the population stagnates and life expectancy develops at a linear rate. The question is then 'why have we been less successful in investments in health than in economic growth'?

It is reasonable that the best-practice path of linearity could be used for forecasting life expectancy for countries still in the catch-up phase, assuming that they have the economic means and incentives to invest in best-practice technology. Countries with a rapid catch-up, like Iceland and Japan, also has the advantage of having a relatively smaller proportion of elderly for several decades, constituting a sort of population momentum, which works in their favour and which helps them to stay on the path of linear advancement. The momentum, however, disappears after some time and then it is likely that they, like their predecessors at the lead, face a downward bend in life expectancy. Few countries finally became world leaders, 
still they tend to be replaced and their life expectancy curve levels off. Thus, new countries are catching up and replacing the former leader and contributing to the linear development of life expectancy.

A parallel within economics can be drawn with the so called Cardwell's Law (Mokyr 1990) economics, which states that no country can maintain technological lead for very long. It implies turnover at the top, just as the case was with regard to life expectancy. Several other economists could be referred to, such as Alexander Gerschenkron who developed the concept of Economic Backwardness (Gerschenkron 1966). Perhaps even more to the point are the concepts of the institutional economist Torstein Veblen, who coined the phrases "the penalty of taking the lead" and "the advantage of borrowing the technological arts". Both phrases refer to the disadvantage of old investments, or in the case of human capital, "aged" capital vis-à-vis new capital. These concepts therefore seem highly relevant to apply when evaluating the significance of low proportions of elderly (i.e. "aged" capital) in populations that has more recently undergone demographic transition, as for example Japan. Will then the future pace of life expectancy in Japan slack as a result of the penalty of taking the lead (population ageing) as has be the case for previous world leaders? And will new countries take the advantage of a backward position and reach the top ranks in terms of life expectancy? My answer is 'yes' on both of these questions.

\section{References}

Barker, D. J. P. (1994). Mothers, babies, and disease in later life. London: BMJ Publishing Group. Befolkningsutvecklingen under 250 år (Population Development in Sweden in a 250-year perspective), Demografiska rapporter 1999:2. Stockholm: Statistics Sweden.

Bengtsson, T. (1998). The great mortality Decline: Its causes and consequences. In C.-E. Núñez Clara-Eugenia (Ed.), Debates and controversies in economic history. Madrid: Fundación Rámon Areces.

Bengtsson, T. (2004). Mortality and social class in Four Scanian parishes. In T. Bengtsson, C. Campbell, J. Z. Lee, et al. (Eds.), Life under pressure. Mortality and living standards in Europe and Asia (pp. 1700-1900). Cambridge, MA: MIT Press.

Bengtsson, T., \& Dribe, M. (2005). New evidence on the standard of living in Sweden during the eighteenth and nineteenth centuries: Long-term development of the demographic response to short-term economic stress. In R. C. Allen, T. Bengtsson, \& M. Dribe (Eds.), Living standards in the past: New perspectives on well-being in Asia and Europe. Oxford: Oxford University Press.

Bengtsson, T., \& Lundh, C. (1999). Child and infant mortality in the Nordic Countries Prior to 1900 (Lund Papers in Economic History, No. 66). Lund: Department of Economic History, Lund University.

Bongaarts, J., \& Bulatao, R. A. (Eds.). (2000). Beyond six billion. Forecasting the world's population. Washington, DC: National Academy Press. 
Brändström, A. (1984). De kärlekslösa mödrarna. Spädbarnsdödligheten i Sverige under 1800 talet med särskild hänsyn till Nedertorneå. Umeå: Umeå University.

Derrick, V. P. A. (1927). Observations on (1) errors in age in the population statistics of England and Wales and (2) the changes in mortality indicated by the national records. Journal of the Institute of Actuaries, 58, 117-159.

Easterlin, R. A. (1999). How beneficent is the market? A look at the modern history of mortality. European Review of Economic History, 3(3), 257-294.

Fogel, R. W. (2004). The escape from hunger and premature death (pp. 1700-2100). Cambridge: Cambridge University Press.

Fridlizius, G. (1984). The mortality decline in the first phase of the demographic transition: Swedish experiences. In T. Bengtsson, G. Fridlizius, \& R. Ohlsson (Eds.), Pre-industrial population change. Stockholm: Almqvist \& Wiksell International.

Fridlizius, G. (1989). The deformation of cohorts: Nineteenth-century mortality in a generational perspective. Scandinavian Economic History Review, 37, 3-17.

Gerschenkron, A. (1966). Economic backwardness in historical perspective. A book of essays. Cambridge, MA: The Belknap Press of Harvard University Press.

Hagskinna. Icelandic Historical Statistics. (1997). Guðmundur Jónsson \& Magnús S. Magnússon (Eds.). Reykjavík: Statistics Iceland.

James, P. (Ed.). (1966). The travel diaries of T.R. Malthus. Cambridge: The Syndics of the Cambridge University Press.

Jörberg, L. (1971). A history of prices in Sweden 1732-1914 (Vol. II). Lund: Gleerups.

Kermack, W. O., McKendrick, A. G., \& McKinley, P. L. (1934). Death rates in Great Britain and Sweden: Some general regularities and their significance. Lancet, 226, 698-703.

Lee, R. D., \& Carter, L. (1992). Modeling and forecasting the time series of U.S. mortality. Journal of the American Statistical Association, 419(87), 659-671.

Maddison, A. (2001). The world economy. A millennial perspective. Paris: OECD.

Mokyr, J. (1990). Lever of riches. Oxford: Oxford University Press.

Nanjo, Z., \& Kobayashi, K. (1985). Cohort life tables based on annual life tables for Japanese nationals covering the years 1891-1982. Tokyo: Nihon University Population Research Institute.

Nordström, L. (1938). Lort-Sverige. Stockholm: Kooperativa förbundet.

Oeppen, J., \& Vaupel, J. W. (2002). Broken limits to life expectancy. Science, 296(5570), $1029-1031$.

Omran, A. R. (1971). The epidemiological transition. A theory of the epidemiology of population change. Millbank Memorial Fund Quarterly, 49(4), 509-538.

Perrenoud, A. (1984). The mortality decline in a long term perspective. In T. Bengtsson, G. Fridlizius, \& R. Ohlsson (Eds.), Pre-industrial population change. Stockholm: Almqvist \& Wiksell International.

Pool, I., \& Cheung, J. (2005). Why were New Zealand levels of life expectation so high at the dawn of the twentieth century? Genus, 61(2), 9-33.

Population Statistics of Japan. (2003). Complied by the national institute of population and social security research. Tokyo: Japan.

Preston, S. H., \& van de Walle, E. (1978). Urban french mortality in the 19th century. Population Studies, 32, 275-297.

Preston, S. H., Hill, M. E., \& Drevenstedt, G. L. (1998). Childhood conditions that predict survival to advanced ages among African-Americans. Social Science \& Medicine, 47(9), 1231-1246.

Riley, J. (2001). Rising life expectancy: A global history. Cambridge: Cambridge University Press.

Sköld, P. (1996). The two faces of smallpox: A disease and its prevention in eighteenth and nineteenth-century Sweden. Umeå: The Demographic Database, Umeå University. 
Tuljapurkar, S., Li, N., \& Boe, C. (2000). A universal pattern of mortality decline in the G7 countries. Nature, 405(June), 789-792.

United Nations. (1953). The determinants and consequences of population trends (Population Studies, No. 17). New York: UN.

Wrigley, E. A., \& Schofield, R. S. (1981). The population history of England 1541-1871. A reconstruction. London: Edward Arnold.

Open Access This chapter is licensed under the terms of the Creative Commons Attribution 4.0 International License (http://creativecommons.org/licenses/by/4.0/), which permits use, sharing, adaptation, distribution and reproduction in any medium or format, as long as you give appropriate credit to the original author(s) and the source, provide a link to the Creative Commons license and indicate if changes were made.

The images or other third party material in this chapter are included in the chapter's Creative Commons license, unless indicated otherwise in a credit line to the material. If material is not included in the chapter's Creative Commons license and your intended use is not permitted by statutory regulation or exceeds the permitted use, you will need to obtain permission directly from the copyright holder. 